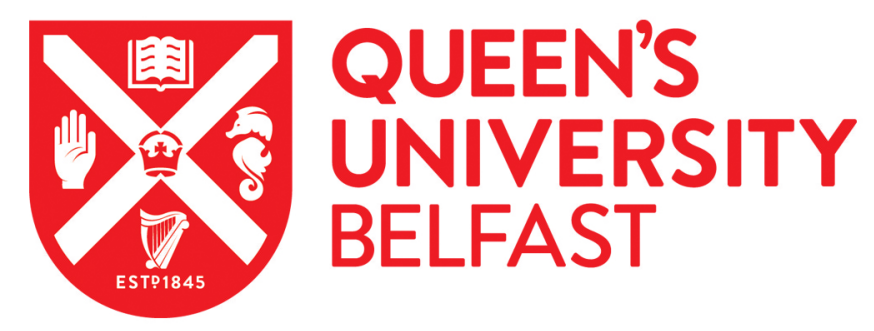

\title{
Influences on the struggle over content: considering two fine art studio practice curricula in developing/ed contexts
}

Belluigi, D. Z. (2016). Influences on the struggle over content: considering two fine art studio practice curricula in developing/ed contexts. Teaching in Higher Education, 21(6), 700-715.

https://doi.org/10.1080/13562517.2016.1183617

Published in:

Teaching in Higher Education

Document Version:

Peer reviewed version

Queen's University Belfast - Research Portal:

Link to publication record in Queen's University Belfast Research Portal

Publisher rights

(C) 2016 Informa UK Limited, trading as Taylor \& Francis Group.

This work is made available online in accordance with the publisher's policies. Please refer to any applicable terms of use of the publisher.

\section{General rights}

Copyright for the publications made accessible via the Queen's University Belfast Research Portal is retained by the author(s) and / or other copyright owners and it is a condition of accessing these publications that users recognise and abide by the legal requirements associated with these rights.

Take down policy

The Research Portal is Queen's institutional repository that provides access to Queen's research output. Every effort has been made to ensure that content in the Research Portal does not infringe any person's rights, or applicable UK laws. If you discover content in the Research Portal that you believe breaches copyright or violates any law, please contact openaccess@qub.ac.uk. 


\title{
Influences on the struggle over content: Considering two fine art studio practice curricula in developing/ed contexts
}

\author{
This paper considers the influences of curricula content on the nuances of \\ teaching and learning practices, and the ways in such influences are complicated \\ by the contexts within which they are situated. Generated data from within the \\ particularity of two fine art schools, one operating from the developed world in \\ the global 'north' and another the developing world in the 'south', considers how \\ they have negotiated the contemporary push from the professional community of \\ practice, led by ‘western’ artmaking, towards the discourse-interest of \\ contextualism in fine art practice education, compared to the focus on skills and \\ mastery of more out-dated formalism. Particular emphasis is placed on the \\ significance of such influences and pressures on the structures and cultures of \\ teaching and learning.
}

\section{The gap between the adoption of global curricula norms and responsiveness to localised contexts}

In a bid to move away from ivory tower conceptions of the university and the 'canon' as homogenising, elitist or imperialist, there has been an emphasis in critical and postmodern traditions in adult education for openness to diversity, inclusion of localised knowledge(s), and a questioning of the relevance of the global to localised contexts, towards curriculum responsiveness (Barnett, Parry, and Coate 2001). However, the 'west' remains strongly influential, particularly in post-colonial contexts, where the historical, philosophical, ideological, economic, cultural et al influences are pervasive, and often implicit. The complex interactions between global and local interests and power dynamics in shaping curricula remains often unacknowledged, and underresearched, particularly at a disciplinary level.

Studies comparing adoptions and translations of internationally borrowed notions in different localised contexts have considered the complexity of implementations of such ideas (Zmas 2014). Whilst others have explored the dynamics 
of relevance in the sub-Saharan region (Alderuccio 2010), this paper contributes to an area of research concerned with the influence of differing socio-economic contexts (Gallwey and Wilgus 2014) and national politics and power relationships (Chisholm 2010) in global North-South interactions. In the process, it explores the significance of the complexities at play when disciplinary curricula 'choices', such as the adoption of ‘western’ norms of contemporary visual art practice, are constrained or enabled by contextual concerns in the developed/ing worlds, and the resultant curricula translations and relevance (raised as a concern in Shah and Quinn 2014).

\section{The struggle over content: curricula of fine art studio practice}

Histories of art education and curricula may be constructed in various ways, including geographical and political schemes (Pearse 1997); historical periods (Elkins 2001) or traditions (Harwood 2007); and national development, human and cultural capital (Stankiewicz 2007). When one researches across geographic locales in these postmodern times, as this study attempts, each of these readings holds validity. Looking across such studies, little consensus on contemporary curricular values in art education emerges. This may be because visual arts has a fundamental ontological/epistemological problem in that it is concerned with defining what art is itself (Harwood 2007), unlike many established disciplines which are concerned with determining what remains within the canon or content of the course, or indeed many other creative arts disciplines. In a previous paper I explored the significance of this problem on transformation and assessment practices in a post-colonial context (Belluigi 2014). In this paper, I expand this discussion to consider how this problem plays out when situated within contextual demands and pressures - firstly within curriculum content, the area best conceptualised within this domain, before considering the significance for larger aspects of the curriculum, including structures and cultures of teaching, learning and assessment - a 
broader understanding of curriculum which in this domain comes from educational development discourses (Belluigi 2015b).

Approaches to course content in 'western' creative art education can be mapped across a continuum. The conservation or preservation of tradition and a generalizable canon can be posited on one polarity, opposed by its destruction or innovation (Harwood 2007). This may be borne of the fundamental differences in disciplinary practices, where some are generally interpretative (such as aspects of theatre and music), and others involve 'original' creations (such as in the visual arts, music composition and creative writing) (Edström 2008). The former's absolutism opposes the latter's relativism, where responsiveness to surrounding cultures or contexts is valourised. Divisions between ‘theory’ and ‘practice’ have perhaps been similarly exasperated in an attempt to establish legitimacy of such 'disciplines' in the academy, with theoretical approaches (whether historical, aesthetic, critical) and so called 'activities of the spirit' (imagination, expression, creation), valorised above practical and technical education (Darras 2007). Echoing the binary of such concepts as the university as ivory-tower or responsive, are the tensions between 'formalist' (art for art's sake) and 'contextualist' (the functional value of art) approaches to artmaking (Anderson and McRorie 1997). In the context of Fine Art Studio Practice (FASP) curricula historically, this relates to the medium-specific formalist interest which dominated during modernism which has largely shifted to a discourse-interest with postmodernism (McEvilley 1996), and attempts to erode the boundaries of so-called 'high art'. Implicitly aligned with this latter emphasis are contemporary contextualist constructions of the artist who extends his/her social, political and historical explorations of the content of the research subject to the form and materiality of the artwork and vice versa. This construction extends to a construction of the ideal artist- 
student in contemporary art schools, with expectations of how they perform such reciprocity in their assessed work (Dallow 2003; Belluigi 2016).

In addition to such influences from the professional community of practice, diverse influences on visual art education include adult learning traditions (Boud 1989) and traditions of creativity (Cowdroy and de Graaff 2007). Those aligned with the critical tradition of adult education enable questioning of the structures that disempower the student; whilst postmodern notions of adult education enable the inclusion and positionality of discourse and the personal narratives of students (Usher and Johnston 1997). There is some recognition of the importance of the conditions for creativity to enable students' metacognition, ability to handle uncertainty and risk-taking (Belluigi 2013).

Often unacknowledged and under-researched, despite awareness of the value of responsiveness and situatedness in terms of curriculum content as described above, is the messy role played by context on such curricular choices. Whilst generating data for a larger research project on authorship in FASP (Belluigi 2015a), I observed tensions emerging from two art schools situated in very different socio-economic and political contexts. In this paper, I represent those aspects of that study which relate to the structure and culture of curricula in FASP, and the significance for constructions and enactments of teaching and learning.

\section{Methodological approach}

Data was generated from one art school situated in the developing world in a rural South African context (which has been differentiated in this text as SAI) and the other operating within a first world, metropolitan context in England (differentiated as UKI). The methodological approach of this study was designed to explore the pertinent 
curricula similarities and differences which emerged, an aspect of which was to be cognisant of contextual influences which have been largely unacknowledged in studies within this domain. A partial aspect of my initial choice to include both institutions was admittedly political and strategic. Very little research in HE art pedagogy is produced, valued or supported in South Africa or on the African continent (McLaren \& Chifenyise n.d.; Mans 2007) where it is not seen as an high-priority in the formal arts education sector, with more research on the arts themselves (McLaren \& Chifenyise n.d., p.12). Only recently are projects such as the Another Road Map Research Project being negotiated, funding for which continuous to be elusive. However, I was aware that claims made from an exclusively African case may be dismissed as too localized to be of significance to an international audience. The inclusion of both locations allowed for the marginal and the mainstream to interface.

This paper emerged from the data collected and generated for a larger study on the complex issues of authorship in this domain (Author, 2015). Once ethical approval has been gained from both institutions, I invited all FASP staff and students involved in the final year of undergraduate FASP at the two institutions, following their requirements and the principles of informed voluntary consent. 9 of 16 staff and 10 of 65 students at UKI actively participated. All 5 staff and 16 students at SAI participated. In my interactions with the staff, I utilized questionnaires, interviews and emails respectively; while with students, data was generated from visual narrative focus group interviews (see Meistre and Belluigi 2010) and follow up emails. In addition, I analysed curriculum documents and made extensive observations of formative and summative assessment interactions. As the assessment system in this domain is of a public nature, the oral assessment discussions and references enabled observation and analysis. In the formative instance in both schools, participants of this process included the artist- 
student being assessed, the artworks and supervisor(s), with the addition of the students' peers and additional faculty at UKI. The summative assessments at both schools involved a panel of expert-assessors who made a collective judgment about the quality of the student's submission. Specifically, at UKI I observed four formative assessments, three internal assessment panels, one internal moderation assessment, two moderation meetings, and a discussion between the external examiners and key staff at the school. At SAI, I observed 6 formative studio assessments, formative and summative panel assessments, and a moderation meeting. The observations spanned an academic year in each context.

I conducted a critical discourse analysis of the data from each source and method. An aspect of my research process involved mining discourses and mapping them to an interpretative framework constructed to analyse both the explicit and tacit interpretative approaches adopted within formative and summative assessment practices (Author, 2015). The framework was composed of a vertical axis with three broad interpretative orientations, which I termed ‘eucharistic', 'objective’ and ‘operative’ criticisms. The horizontal axis distinguished between references made to the author/artist, text/artwork or reader/viewer. I utilised a schema which visualises the conditions for creativity in this domain (Belluigi 2013) to analyse the significance of those interpretative approaches on the quality of student learning. The schema was useful as it holistically interweaves the creative student's sense of self and identity as the author; the creative process; and the creative outcome or product, visualised at each apex of a creativity triad, which is situated within certain conditions which enhance, constrain or maintain student engagement. I 'bounced’ my triangulated interpretations off the participating staff for further discussion, challenge or insights into the problematics that arose, utilising a 'report-and-respond' approach (Stronach and 
McLure 1997). As such they were actively involved as participants throught the data generation and analysis process, such being provided opportunities to comment on my interpretation of the literature in the questionnaire, then later in the interview on my interpretations based on triangulation of those responses, data from students, my observations and curriculum documentation. As I had previously taught within this domain and practiced artmaking, I was able to utilise the academic and professional discourses with which the participants were most comfortable, whilst at times contrasting these with those of educational development, where I am currently situated.

\section{Considering the developing/ed context of the cases studied}

Whilst the socio-economic contexts of the two schools would seem to differ greatly on the surface from those outside of the domain of fine art practice, both higher education institutions espoused very similar approaches to adopting ‘western’ systems of art education and contextualism in their curriculum content. Through the colonialist project, South African art education was developed through British cultural imperialism (Stankiewicz 2007) and still maintains strong links with British artistic identity (Mans 2007). Fundamentally, both schools were concerned with producing graduates who would practice artmaking within contemporary art.

However, the national and continental context emerged as playing a dominating role in the formalist leanings of SAI, as 'in terms of resources as a South African artist, you have to be able to do things yourself', as one staff member articulated. For many reasons, very few eligible students apply for, and even fewer succeed in, FASP studies in South Africa. Some of the reasons for such problems in access and success include: that South Africa is currently the most economically unequal society on earth (The World Bank 2013); the apartheid educational system which disadvantaged and excluded individuals from specific demographics from HE; delayed massification; neoliberal 
pressures for 'developing' countries to produce a skilled rather than critical or creative labour force (Paasche 2006); and a growing nouveau riche community which values education leading to economic excess over cultural production (Scott, Yeld, and Hendry 2007). The influence of this was most evident in the demographics of those registered for undergraduate studies at SAI, being mostly upper to middle class white female students, with a growing minority from the rising black middle classes. The economic reality is that few African artists can afford the time or money to enrol in formal studies with much education occurring through informal networks (Raw Material Company 2012).

As the amount of enrolments each year exceed the amount of practicing artists in the sector (Gaylard and Hagg 2011), few who are awarded such degrees become practicing fine artists. There is little state support for the arts and corporate incentives to invest are minimal, with the majority of so-called successful artists having to generate their own financial support for their practice through employment in other sectors and over $57 \%$ having been unable to generate income for significant periods of time (Gaylard and Hagg 2011). Staff at SAI were cognisant of this, articulating that all national Bacher of Fine Art degrees functioned pragmatically as the debut show for professional practice, with Masters studies perceived as the terminal degree mostly for academic purposes. Power in the art market sits with gallerists who mainly have connections outside of the country, as is the case in a number of other African countries (for instance see Silk 2011). As such, competition over this small pie is rife, collaboration less emergent than individual practice (6\% compared to 60\%, Gaylard and Hagg 2011), with high expectations in the standard of production.

In the United Kingdom, in comparison, a far higher percentage of the population is literate in addition to being more financially empowered and culturally aware, with 
more economic resources and diverse communities of support available to artists. The UK is acknowledged as at the top of the hierarchy for sales in the art market in the EU, and the largest importer and exporter of art globally (McAndrews 2013). These were some of the reasons staff at UKI cited to explained why there was not as much ferocity in the competition between artists and why more artists undertook postgraduate degrees in the UK (over $9.7 \%$ as indicated in the graduate destinations data of the HESA 2014), which the UKI staff saw as the national expectation for entry into professional practice.

Whilst the data for this study was generated in 2013, before the full implementation of the 2012/2013 tuition reforms in the UK, the influence of changes in the balance between public and private contributions to HE funding were already beginning to show. The shift in responsibility from state to the individual, as part of the UK 'cost-saving agenda' which had begun in the 1990s (Kilkey et al 2012), not only continued to increase student contributions to tuition fees but also promoted the marketization of HE. Undoubtedly, this issue emerged palpably in assessment discussions and interviews as of concern for all the staff at this school, with a sense of the student as consumer within the changing fee structure. The power shift this engendered, in an attempt to address customer satisfaction, was identified by the Director of Studies (DiS) as a pressure particularly around assessments, where she noted assessors exhibited fear of 'a come-back'. Staff articulated the importance of students having enjoyed their university experience, over and above what they learnt or produced. In their interviews with me, three of the staff highlighted how student feedback, collected through the National Student Survey, had a certain degree of power and influence in this context, albeit that the perceptions of the effectiveness of such methods for quality assurance and development have been recognised as varied (NatCen 2015). 
This paper contributes to studies interested in the complexity emerging from socioeconomic disparities and differing cultural values and understandings (such as Fung 2014; Tan and Chua 2014). In the following sections, I discuss how the comparative case study confirmed research which suggests that the national context is influential to translations of international ideas and has significance for individual agency and supposed 'choice’ to transcend contextual influences (Moreau 2014).

\section{A comparative analysis of curricula approaches to content and form}

As discussed in the introduction to this paper, with changes to the relationship of form and content in contemporary art, a shift has been made in contemporary FASP curricula away from formalism towards contextualism, and with that, from medium-specificity towards discourse-interest.

When analysing each case, UKI was more distinctly characterised by contextualism, with artworks operating within this orientation rewarded, and content seen as more important than form as 'processes follow the idea' (the Head of Department (HoD). UKI's construction of the undergraduate degree was as an introduction rather than specialisation with the overall aim being, as articulated by the HoD and DiS, to challenge and broaden the mostly "immature” preconceptions of their students (the majority being under 21 years old) , rather than develop their skill-base.. The curriculum was designed to enable students to choose the pace, subject and mediums of their projects, with assessment events as the only imposed constraints. Studio practice was differentiated into two modules. From the outcomes, criteria and staff descriptions, the 'Studio Practice module' developed and assessed the quality of processes of composition and production of the artwork, as well as instilling and rewarding certain behaviours ('studentship'). From their first year, students had access 
to learn a number of mediums through ad hoc, short-term workshops. The 'Exhibition/Portfolio and Professional Development' module included the additional criterion of 'selection, presentation and audience', thus including reception. As articulated to me by the DiS, the intended purpose behind the two modules was for both the artmaking process and the final artefact or product to be recognised in the assessment process, and for that to backwash to student learning and their experience as consumers. Thus the expected summative submission included one to three exhibited works, a portfolio, research log and possible additional back-up material.

My analysis revealed that SAI straddled both contextualism and formalism with remnants of medium-specificity. The accent was on the reciprocality of form and content, with an expectation of sophistication in both areas. Towards this, the structure of the FASP major incorporated a broad introduction of discourse-oriented projects in set mediums, to engage students with all mediums during the first two years. The last two years offered students a choice of specialised medium-specific instruction under an individual practitioner. Only towards the end of this did students have choice of research subject in their preparation for the solo submission exhibition. Through formal and informal means, students were familiarised with the histories and discourses of practice around the mediums, towards an applied and abstract understanding of how the specifics of form might add to the meaning, experience or interpretation of their work. Despite acknowledging the constraints and outdatedness of this 'unfashionable' medium-specific structure, many staff articulated the benefits for their students, such as comprehensive and sophisticated knowledge of at least one medium and its discourse, and a reputation for quality that the school had gained.

In contrast to UKI's concern with the student-consumer's experience, an emphasis on mastery of technique and skills was evident when 'students very quickly 
realize that they're not going to be really entertained if they're mediocre' (HoD). As the final assessment was an assessment-by-exhibition, without a portfolio, reflective documents or differentiated assessment criteria to negotiate the relationship between 'process' and 'product', the backwash from this event was that the 'product' took precedent over the student's learning experience or development. All of the SAI staff felt this was justified as it mirrored the focus of the community of practice on 'the product, the world is not looking at your learning'. The summative expectation was much higher than that of the national qualifications framework of an honours level bachelor’s degree (CHE 2014), being comparable to a Masters, because the degree functioned as a debut show. It was explained to my interviews that any less than this would not prepare students adequately for their entry to professional practice in the national context, where competition was fierce.

... there is no framework that young artists in South Africa can fall back on, there are no community centres, there's no support groups, there's no artist groups. So you're on your own. I suppose it's to give them that kind of bases now ... you've got a body of work that you can present in whatever context, so you're already ahead.

This echoes similar frustration and anxiety about competition and success in the art market, impacting on risk taking during students’ studies, expressed by staff and students in other African studio learning contexts (Silk 2011).

\section{The structural and cultural significance on teaching}

Of importance is the significance of such tensions between curricula and contextual influences on teaching and learning. Those informed by formalist approaches are accused of creating environments where students are encouraged to reproduce the known; contextualist approaches are accused of encouraging students to produce the 
unknown of the present (Darras 2007). Similar binaries are evident in higher education studies, where teacher- or curriculum-centeredness is often pitted again student or learning-centeredness (Dewey 1902), with student voice/ demands/ desires placed in opposition to the authority of the teacher as representative or reproducer (Bourdieu 1977) of the professional or academic community. In this study, the tensions played out on how staff roles were constructed, as assessors and as teachers, and on how learning was constructed.

In their group marking events, both schools operated as stable interpretative communities. Assessment in this tradition is of an informed agreement following debate and negotiation among a rational 'interpretive community’ (Fish 1980). However, it emerged that the ways in which individual members were constructed was influenced by the curricula approaches.

The medium-specificity at SAI impacted on their panel assessment practices. Each individuals’ role was constructed as representative of a medium-specificity, with related expertise more clearly and explicitly valued than the person's interpretations of the artwork in any other capacity during assessment, resulting in a dominance of objective criticism (i.e. a focus on the formal, aesthetic properties). In comparison, the structure at UKI was shaped by adherence to outcomes-based assessment. Roles were assigned to the three staff members of each panel: one as the 'supervisor' of the student, and the other two arbitrarily assigned as assessors of particular modules, with their judgments bounded by explicit criteria.

Much of this hinged on each schools’ construction of practice-based teaching. As with most studio practice education, experiential learning was recognised in both schools, including participation in practice (Danvers 2003). In part influenced by the 
curricular differences discussed in this paper, this was practiced very differently at the two schools.

Amongst key players at UKI was a debate as to how much and in what ways structures should be created or removed for staff to share their practice, a debate which echoed conflicts between educational and professional discourses (Belluigi, 2015). Interaction between staff and students did not involve sharing staff members’ specific practice, nor even the in-and-outs of processes of students' thinking and making in relation to shared discourses, as these emerge during students' production processes. Moving away from the traditional model, the studio at UKI was constructed as a 'learning' space of peer interaction rather than for 'teaching' in the staff members' discussions directly with me, and in the structural arrangements of their interactions with students, which rarely occurred within the studio. The one interviewed staff member who deviated from this norm justified doing this only in exceptional circumstances. Constructions of staff roles at UKI had shifted from a strongly mentoring role of the studio atelier model, where student and supervisor work alongside each other as the student learns-by-doing in the studio (Belluigi 2016), to facilitation within formal assessment events held in exhibition-type venues. The culture placed little emphasis on student presence in the studio, due to the contextualist emphasis on 'concept' rather than hands-on skills; and economic constraints which included pressures on space per capita and limited availability of staff for formative interactions, the majority on part-time or casualised contracts. The reduced interaction with staff was the main reason cited by students to explain their lack of surety of assessment expectations, as they could not familiarize themselves with the school's habitus (the idiom 'a fish out of water' was most commonly used by students in the focus group discussions). 
Related was an emphasis on what was commonly termed 'self-directed learning' at UKI. Students were given autonomy to choose their projects, and for the most part set their own parameters. 'Self-management' was a term utilised in course documentation to balance such autonomy with an accent on student responsibility. When experiences of this were highlighted in the focus group interviews, all students expressed that, with little structure or interaction in studio with the staff, the pressures of high-stakes assessment were frightening. Similar responses have been reported in other self-directed learning structures where modelling has been reduced (Harwood 2007).

In comparison, student learning at SAI was greatly scaffolded. The students' relative developmental immaturity as artists, when coupled with the push towards finish and product at such a higher level, created a necessity for staff guidance and support. SAI utilised studio learning in traditional ways for this domain, with students spending considerable time in that space daily, interacting informally with peers and staff. Emerging from the medium-specific accent at SAI was the figure of the artist-teacher as expert medium-specialist. Intensive interaction during conception and production processes in the studio enabled staff at SAI to communicate empathetic responses and solidarity as fellow image-makers when students experienced uncertainty. In the studio formative assessments I observed, when staff shared the specificity of their knowledge of the medium, its processes and its history, in relation to particular aspects of the student's practice, students were appreciative. This was confirmed during the focus group interviews particularly, such as by this student who articulated appreciating the formative guidance of medium experts, in particular her medium-specialist supervisor who was able to guide technical aspects and who valued her labour and processes.

I sort of feel like, particularly with X [medium], you do so much stuff. You know, there is so many different processes that are involved... maybe that's why I prefer 
$\mathrm{X}$ \{medium-specific artists] looking at my work. There's an understanding there, there's someone who like is going 'Wow, that must have taken you forever'.

In an email correspondence, another student indicated he received his supervisors’ guidance differently because of his respect for her practice.

$\mathrm{X}$ [supervisor] is an extremely adept $\mathrm{X}$ [medium expert] so knows she how to give very good advice when I am busy with a work.

One student specifically referred to the value of having a supervisor who could provide “sophisticated” guidance both conceptually and technically, and how a lack of such dual capacity would invalidate that role.

I don't think anybody else, if they haven't done it, they don't know how to use the program, they don't know how to... they couldn't teach me how to do it. I don't think so, really.

The majority of students as SAI indicated that the shift to a single staff relationship within the medium-specific context, coupled with having more autonomy of choice in the last two years of study, helped them gain greater surety and security in their learning process. However, the power of such relationships was reduced at summative assessments, where implicit individuated curricula and negotiated criteria were undermined by the focus on the product.

\section{The significance for constructions of learning}

Emerging from these curricula influences, and underpinning their formative and summative assessment practices, were different constructions of learning. UKI operated within the andragogy tradition of adult learning (Boud 1989). Attempts to remove many of the perceived constraints of formal education and the canon were most particularly evidenced in the emphasis on self-directed learning. In its medium-specificity, SAI had 
weak accents of the training and efficiency tradition (Boud 1989), with a more explicit emphasis from the critical adult education tradition (Boud 1989) when it came to questioning bodies of knowledge and representation. Whilst the previously formalist curriculum now embraced contextualism, there had been little conscious reconsideration of the assessment practices and learning conditions at the school, perhaps because there was little buy-in to educational discourses (Belluigi 2015b). This was in contrast to UKI, where the influence of such national discourses had impacted on staff appointments at a senior level (overseeing such change was the DiS’s mandate); curriculum innovations and changes to assessment structures (including criterionreferenced assessment and more inclusivity of material to aknowledge the process of learning).

A distinct accent at both schools was for students to push their own boundaries. FASP takes the 'knowledge capability’ approach of problem-based learning a step further, where solving problems is at a lower level of learning than the divergent and exploratory problematizing necessary for the development of contemporary artists (Corner 2005). In both schools, this was enabled through the contextualising curricula which engaged students in problematizing the discourses they operated within. However, innovation emerged on a micro- rather than macro-level, or what has been distinguished as psychological creativity (p-creativity). This is defined as being novel in terms of the individual's thought processes and creating change in that persons' conceptual framework; compared to historical creativity (h-creativity), defined as encompassing the individual aspect of psychological creativity and going beyond that to being novel in terms of human history (Boden 1994). When offered this interpretation, the HoDs at both schools thought this was probably appropriate for undergraduate level. 
Acknowledging the fundamental indeterminacy of contextualist artmaking and the inherent instability born from dynamic and productive critical interrogation, risk, play, re-working and reconsideration (Danvers 2003; Hanney 2012), risk and experimentation were espoused as having prominent positions within the summative assessment process at UKI. This was structurally acknowledged through the inclusion of back-up material acting as ‘extensive documentation’ of process (DiS). In the focus group interviews, a few students perceived that risk was rewarded within formative assessments, such as when a student described being advised to explore works had the potential not to succeed and being encouraged to ' 'fail' in the sense of try it out even though it won't work'. However, I observed that in summative assessments discussions of these criteria were complicated by students’ dispositions, cultural capital, and relationships with staff, and not consistently applied across the board.

At SAI, only the students considered by staff to be the most accomplished were permitted to take some risks in their final year. One student spoke about knowing that, because of her "proven track-record" of technical proficiency and "delivering”, she had earned the liberty to push beyond those parameters. This students' narrative indicated how assessors made calculations based on their surety that risks would not jeopardize success. It emerged that the vast majority of students realised too that the principle of safety to risk was not supported by the assessment structures which disallowed extended periods of uncertainty. The pressure to be strategic in the face of the drive for a finished product, particularly for those constructed as 'weak', often resulted in alienation from process. In an email, a student noted the panel’s risk-aversion, “I think that our engagement with 'play' in art is promoted in theory, by this I mean they encourage us to play but seem apprehensive towards the result of this”. Because they mediated between assessment and teaching, "the guidance of our superiors sometimes shadows and 
influences our process to the point where it can cause rigidity and predictability within our processes”, as another student expressed during the focus group interview.

When discussing this during interviews, four of the five SAI staff felt this unfortunate but appropriate, as the risk of failure in the product orientated curriculum would be devastating. One staff member articulated in an interview that 'it makes me nervous if there is too much play and no resolution, I feel my job is to guide solution'. Recognizing, from her own experiences as a student, that learnt self-preservation undermines creativity, she saw her role as protecting her students by helping them make calculated risks to achieve success within the anti-intentionalist (i.e. exclusionary of authorial knowledge to inform interpretations) assessment framework of the school. The differences, in the two schools’ approaches to risk, confirms arguments that sociocultural and socioeconomic conditions play a role in risk-aversion during arts studies.

The majority of students in both schools came with a lack of critical cultural capital to fundamentally question and challenge themselves (similar to the observations of Jackson 2013). However, they were encouraged, and in different ways enabled, to adopt critical stances to their own artmaking, with a strong expectation that received opinions, ideological positions, and common-sense assumptions be challenged to create an appreciation of the ‘inherent revisibility of knowledge’ (Danvers 2003, 51).

In addition to this critical accent on the subject content, the culture at SAI was to challenge conservative understandings of art prevalent nationally, although the dominance of 'western' contemporary aesthetics seemed unchallenged. A more critical than appreciative or representational approach was rewarded at SAI, with descriptions such as 'sinister’; ‘challenging'; ‘ambiguous’ valorised above ‘too pretty’; 'didactic’; 'depictive'; 'illustrative’; 'tame'. While aspects of criticality were evident at UKI, my 
observations revealed there was far more allowance for lighter aspects, such as curiosity and playfulness.

A valued characteristic of SAI was for research to have 'personal' relevance. This accent seemed to come from the critical inward-looking of the national art community (Herreman and D’Amato 1999) possibly because of 'historical melancholia' (Belluigi 2001) in the face of a crisis of representation in that post-colonial and postapartheid context, still strongly felt by the practice-based staff. It avoided the quagmire of sensitivities prevalent during their own education (Atkinson and Breitz 1999). This insularity may have influenced the emphasis on formal elements of the work, not dissimilar to the 'flight from judgment' to avoid the 'burden of historical judgment' noted in current art criticism (Elkins 2013). It bears remembering that the formalist emphasis on the 'purely optical' arose specifically in post-war 'western’ culture following a sense of political helplessness, and was seen as an indication of an unconscious, insular disposition of social alienation and withdrawal from the world (McEvilley 1996; Habib 2005). However, because of the anti-intentionalist interpretativst approach of the assessment practices at SAI, such authorial knowledge about the students' relationship to the content and form of the artwork was abstracted away from the individual.

The possibilities of perspectivism, where critical evaluation allows space to exhibit diversity, difference, and pluralism (Danvers 2003), were created through peer interaction at formative assessments at UKI. Although this purpose was not explicitly communicated verbally by staff or in curriculum documents to students, such formative assessment events were structured to engage students with how their aims corresponded or complicated with public reception (DiS; HoD). A minority of the participating students indicated that such formative events were where they learnt the most, as the 
accent of reader-response from their peers resulted in 'the most direct and varied responses about work', as one student articulated in the focus group interview.

However this was not the experience of those students who operated outside of the school's conceptual expectations. One such student described the feedback and reception of his artwork as homogeneous, going so far as to characterise staff as having 'the same mentality’ and 'being the same person'. The larger contextualist framework, within which feedback from this school was bounded, made no allowance for the desires of those outside of this norm. The HoD of UKI reiterated in an interview that work which operated outside of the norms of contemporary art practice 'would not be rewarded'.

Similarly, having ideas dismissed by staff, because the students’ approaches were judged as 'too literal', 'too obvious', resulted in students at SAI often capitulating to more strategic choices to succeed. One student believed that SAI staff had disregarded her because of their estimation of her lacking 'conceptual' capacity, which she in turn internalised. When I articulated this observation of her narrative directly to her, this student explained that although the assessors' response was to the artwork, she internalised that as a criticism of her identity, so that something inside her 'died a little bit; it died a lot'. The privileging of conceptual thinking over material responsiveness had been similarly adopted by students at both schools.

Perhaps because they were straddling the contextualist and formalist divide, some SAI staff members felt it necessary to foreground the perspectivism and provisionality of different discourse communities during formative studio interactions with their students, as this staff member described. 
I now understand artmaking and the world as a pluralistic and multi-dimensional realm, where context starts to become ever-increasingly important. In one school work may be amazing but in another it may be weak.

Many of the staff recognised that this, in part, had to do with negotiating the ideal of contemporary art discourse-interest in face of the more pressing and tangible realities of professional practice, when operating at the periphery in a post-colonial context with limited resources and the pressures of reward from the imperialistic gaze. They felt that students would need to negotiate such frameworks, and develop their own position in relation to them.

However, assessment expectations constrained and sometimes nullified the individuated curricula evident within the studio. The immediate pragmatic summative assessment expectation of a 'better' product created anxiety for staff to take responsibility for assuring the ‘direction’ of student work towards resolution, with related synonyms and metaphors utilized in all assessment events. 'Refinement' and ‘resolution' emerged as implicit criteria to define distinctive work. Staff were aware that for many students the push for excellence and accent on the product could result in failure, ultimately damaging for the student-artist professionally and affectively.

Despite the supposed latitude enabled by the sociocultural and economic conditions in the UK, the dynamics of the summative assessment practices in both schools emerged as similar. Because of the sharply hierarchical power structures of the summative assessments in both schools, where students themselves were excluded and their self-assessments not given priority, individuated and/or multiple perspectives (whether of the artist-student, peers or staff) were not exercised as horizontal when interpreting the work. Many of the staff at both schools acknowledged that despite attempting to establish enabling conditions for creativity, because of the backwash of the power of summative assessments, most often students practiced a balance between 
calculated risk and risk-avoidance, thinking strategically for better grades or social validation from the staff. Thus whilst both schools espoused contextualist approaches to content, because of the summative approach and its backwash on student agency and under-development of metacognition, neither could be positioned sitting strongly within critical nor postmodernist traditions of adult education.

The importing of anti-intentionalist approaches from ‘western’ contemporary art criticism is in sharp contrast to feminist (Miller 2000) and postcolonial demands for authorial agency (Ni Fhlathiun 1995), which has been echoed in criteria for social justice art education (Dewhurst 2011). Neither school had reckoned with the ethicopolitical dangers of divesting the student-author power to respond authoritatively to readings of his/her text. As an alternative approach which may better develop metacognition, Burke (1995) points to a tradition of situating rather than detaching the subject from the text and world.

The implications of such aspects of the assessment cultures for the schools’ mandate, to develop artists within the current contextualist ethos of contemporary art practice, is disquieting.

\section{Conclusion}

This paper has looked specifically at the influence of different curricular influences on the structure and culture of teaching, learning and assessment practices in two cases of undergraduate studio practice. While attempting to operate within a similar paradigm, both espousing developing graduates for practice within contemporary fine art practice, differences emerged. With UKI located in England and SAI in South Africa, the influence of economic power, from the global art market to national resources and expectations, impacted on the realities of the professional community of practice, which 
the academic staff attempted to negotiate through assessment structures and their own agency. UKI had a more discourse-specific approach to teaching and learning, while SAI straddled that and formalism, to enable more skills in their graduates to compete more effectively. These influences impacted on how teaching and learning was constructed and affected. A concern is raised that, regardless of the intentions behind the curriculum approaches taken, the hierarchical relationship and exclusionary antiintentionalist dynamics of summative assessment at both schools, impacted on the possibilities for developing a safe environment for risk, uncertainty and metacognition, necessary conditions for creativity if students are truly to operate with criticality within contemporary artmaking.

\section{Reference list}

Anderson, T., \& McRorie, S. (1997). A Role for Aesthetics in Centering the K-12 Art Curriculum. Art Education 50(3): 6-14.

Alderuccio, M C. (2010). An Investigation of Global/local Dynamics of Curriculum Transformation in sub-Saharan Africa with Special Reference to the Republic of Mozambique. Compare: A Journal of Comparative and International Education 40 (6): 727-39.

Atkinson, B., \& Breitz, C. (1999). Grey Areas. Johannesburg: Chalkham Hill Press.

Barnett, R, G Parry, and K Coate. (2001). Conceptualizing Curriculum Change. Teaching in Higher Education 6 4): 436-49.

Belluigi, D. Z. (2001). Broken Vessels: The Im-Possibility of the Art of Remembrance and Re-Collection in the Work of Anselm Kiefer,Christian Boltanski, William Kentridge and Santu Mofokeng. Master of Fine Art thesis, Rhodes University, Grahamstown.

Belluigi, D.Z. (2013). A proposed schema for the conditions of creativity in fine art studio practice. International Journal of Education \& the Arts 14(19), 1-23.

Belluigi, D. Z. (2014). The paradox of "teaching” transformation in fine art studio practice: assessment in the South African context. International Journal for Education through Art 10(3):.349-362. 
Belluigi. (2015a). The problem of authorship: considering the significance of approaches to interpretation on the conditions for creativity in undergraduate fine art studio practice. Unpublished doctoral thesis, Kinston University, London. http://eprints.kingston.ac.uk/32459/

Belluigi, D. Z. (2015b) The significance of conflicting discourses in a professional degree: assessment in undergraduate fine art practice, Discourse: Studies in the Cultural Politics of Education.

Belluigi, D. Z. (2016). Constructions of roles in studio teaching and learning. International Journal of Art and Design Education 35(1): 21-35.

Boden, M. A. (1994). “What Is Creativity?” In Dimensions of Creativity, edited by M. A. Boden, 75-118. Cambridge, Mass: MIT Press.

Boud, D. (1989). “Some Competing Traditions in Experiential Learning.” In Making Sence of Experiential Learning, edited by S. R. Weil and Ian McGill. Milton Keynes: Open University Press.

Bourdieu, P. (1977). Reproduction in Education, Society and Culture. Newbury Park, California: Sage.

CHE (Council on Higher Education). (2004). South African Higher Education in the first decade of democracy. Pretoria: Council on Higher Education.

Chisholm, L. (2010). The Politics of Curriculum Review and Revision in South Africa in Regional Context. Compare: A Journal of Comparative and International Education 35(1): 79-100.

Corner, F. (2005). Identifying the Core in the Subject of Fine Art. International Journal of Art \& Design Education 24(3), 334-42.

Cowdroy, R. \& Williams, A. (2007). Assessing Creativity in the Creative Arts. Art, Design \& Communication in Higher Education 5(2), 97-117.

Dallow, P. (2003). Representing Creativeness: Practice- Based Approaches to Research in Creative Arts. Art, Design \& Communication in Higher Education 2(1/2), 4966.

Danvers, J. (2003). Towards a Radical Pedagogy: Provisional Notes on Learning and Teaching in Art \& Design. Journal of Art \& Design Education 22(1), 47-52.

Darras, B. (2007). International Commentary, France. In International Handbook of Research in Arts Education, edited by Liora Bresler, 31-34. Dordrecht: Springer. 
Dewey, J. (1902). The Child and the Curriculum. Chicago, Ill.: University of Chicago Press.

Edström, A-M. (2008). Art Students Making Use of Studio Conversations. Art, Design \& Communication in Higher Education 7(1), 31-44.

Elkins, J. (2013). What Happened to Art Criticism? Chicago, Ill: Prickly Paradigm Press.

Fish, S. (1980). Is There a Text in This Class: The Authority of Interpretive Communities. Cambridge, Mass: Harvard University Press.

Fung, D. (2014). Expectations versus Reality: The Case of Liberal Studies in Hong Kong’s New Senior Secondary Reforms. Compare: A Journal of Comparative and International Education.

Gaylard, J. \& Hagg, G. (2011). National Study on the Visual Arts Sector. Pretoria: Visual Arts Network of South Africa.

Gallwey, S. \& Wilgus, G. (2014). Equitable Partnerships for Mutual Learning or Perpetuator of North-South Power Imbalances? Ireland-South Africa School Links. Compare: A Journal of Comparative and International Education 44 (4): 522-44.

Hanney, R. (2012). Are we any good at it: Using risk as a tool for reflection and critical enquiry: Report of research in progress. Art, Design \& Communication in Higher Education, 10(1), 103-109.

Harwood, E. (2007). Artists in the Academy: Curriculum and Instruction. In International Handbook of Research in Arts Education, edited by Liora Bresler, 313-30. Dordrecht: Springer.

Herreman, F. \& D’Amato, M. (1999). Liberated Voices: Contemporary Art from South Africa. Prestel.

HESA (Higher Education Statistics Agency). (2014). Higher Education Statistics for the United Kingdon 2012/13. PR208. London: Higher Education Statistics Agency.

Hoskins, B., Janmaat, J. G., Han, C.\& Muijs, D. (2014). Inequalities in the Education System and the Reproduction of Socioeconomic Disparities in Voting in England, Denmark and Germany: The Influence of Country Context, Tracking and Self-Efficacy on Voting Intentions of Students Age 16-18. Compare: A Journal of Comparative and International Education. 
Jackson, M. (2013). The Squeezed Middle: An Exploration of Creativity, Conformity and Social Class on the Academic Achievement of Undergraduate Students within a UK Art School. International Journal of Art \& Design Education 32(3), 345-51.

Kilkey, M., Ramia, G., \& Farnsworth, K. (2012). Spatial Policy Review: Analysis and debate in social policy. London: Policy press.

Mans, M. (2007). International Commentaries: Namibia. In International Handbook of Research in Arts Education, edited by Liora Bresler, 63-64. Dordrecht: Springer.

McAndrews, C. 2013. The TEFAF Art Market Report 2013. Arts Economics for The European Fine Art Foundation.

McEvilley, T. (1996). Capacity: History, the World, and the Self in Contemporary Art and Criticism. Critical Voices in Art, Theory and Culture. Amsterdam, Netherlands: G+B Arts International.

McLaren, R., \& Chifenyise, C. (n.d.). Research capacities in arts education and their practical applications in the southern African sub-region. UNESCO. Retrieved 21 January 2015 from http://www.unesco.org/culture/en/artseducation/pdf/writtencontribution307rober tmclarenfullpaper.pdf

Meistre, B. \& Belluigi, D. Z. (2010). After Image: Using Metaphoric Storytelling. In Teaching Creativity - Creativity in Teaching, edited by Claus Nygaard, Nigel Courtney, and Clive Holtham. Oxfordshire: Libri Press.

Miller, N. K. (2000). Changing the subject: Authorship, Writing, and the Reader. In S. Burke (Ed.), Authorship: From Plato to the Postmodern: A Reader (pp. 193212). Edinburgh: Edinburgh University Press.

Moreau, M. (2014). Becoming a Secondary School Teacher in England and France: Contextualising Career 'choice’. Compare: A Journal of Comparative and International Education.

NatCen, 2015. Review of the National Student Survey. Report to the UK Higher Education Funding Bodies. London: NatCen Social Research.

Paasche, K. I. M. (2006). An Analysis of South Africa's Education Policy Documents: Self-Definition and Definition of the “Other”. Lewiston, N.Y: E. Mellen Press. 
Pearse, H. (1997). Imagining a history of Canadian art education. In A. A. Anderson \& P. E. Bolin (Eds.), History of art education: Proceedings of the third Penn State international symposium (pp. 16-25). University Park, PA: Art Education Program, School of Visual Arts and the College of Arts and Architecture of the Pennsylvania State University.

Raw Material Company. (2012). Condition Report: Symposium on Artistic Education in Africa.

Schiralli, M. (2002). Anxiety and Uncertainty in Aesthetic Education. Journal of Aesthetic Education 36(2), 52-66.

Scott, I., Yeld, N. \& Hendry, J. (2007). A Case for Improving Teaching and Learning in South African Higher Education. Higher Education Monitor 6. Cape Town: CHE.

Shah, R and Quinn, M. (2014).Mind the Gap: Global Quality Norms, National Policy Interpretations and Local Praxis in Timor-Leste. Compare: A Journal of Comparative and International Education.

Silk, J. (2011). The Pedagogy of Failure in the Global Market. International Journal of Art \& Design Education 30(1), 45-51.

Stankiewicz, M. (2007). Capitalising Art Education: Mapping International Histories. In International Handbook of Research in Arts Education, edited by Liora Bresler, 7-30. Dordrecht: Springer.

Stronach, I. \& MacLure, M., 1997. Educational research undone: the postmodern embrace, Philadelphia, Pa: Open University Press.

Tan, C., \& Chua, C. (2014). Education Policy Borrowing in China: Has the West Wind Overpowered the East Wind? Compare: A Journal of Comparative and International Education.

The World Bank. (2013). South Africa Economic Update. Focus on Financial Inclusion. Africa Region Poverty Reduction and Economic Management 4.

Usher, R. \& Johnston, R. (1997). Reconfiguring the Other. Self and Experience in Adult Education. In Adult Education and the Postmodern Challenge. Learning beyond the Limits, edited by Robin Usher, Ian Bryant, and Rennie Johnston, 94-121. London: Routledge. 
Zmas, A. (2014). Global Impacts of the Bologna Process: International Perspectives, Local Particularities. Compare: A Journal of Comparative and International Education. 